\title{
Vitamin D Status in Children With Hemato-Oncological \\ Diseases in Northern Finland
}

\section{Lumme, Johanna}

2019-02

Lumme , J , Mottonen , M , Pokka , T , Makitie , O , Harila-Saari , A \& Niinimaki , R 2019 , '

Vitamin D Status in Children With Hemato-Oncological Diseases in Northern Finland ',

Clinical Pediatrics , vol. 58 , no. 2 , pp. 241-244 . https://doi.org/10.1177/0009922818806310

http://hdl.handle.net/10138/309776

https://doi.org/10.1177/0009922818806310

unspecified

publishedVersion

Downloaded from Helda, University of Helsinki institutional repository.

This is an electronic reprint of the original article.

This reprint may differ from the original in pagination and typographic detail.

Please cite the original version. 


\section{Vitamin D Status in Children With Hemato-Oncological Diseases in Northern Finland}

Clinical Pediatrics

2019, Vol. 58(2) 24I-244

(c) The Author(s) 2018

Article reuse guidelines:

sagepub.com/journals-permissions

DOI: $10.1177 / 0009922818806310$

journals.sagepub.com/home/cpi

@SAGE

\author{
Johanna Lumme, MD ${ }^{1,2}$, Merja Möttönen, MD, $\mathbf{P h D}^{1,2}$, \\ Tytti Pokka, MSc ${ }^{1,2}$, Outi Mäkitie, MD, PhD ${ }^{3,4,5,6}$, \\ Arja Harila-Saari, MD, PhD ${ }^{7}$, and Riitta Niinimäki, MD, PhD ${ }^{1,2}$
}

\section{Introduction}

The most important vitamin D source is cutaneously formed vitamin $\mathrm{D}_{3}$ (cholecalciferol) after exposure to ultraviolet $\mathrm{B}(\mathrm{UVB})$ radiation from sunlight. ${ }^{1}$ At latitudes above $37^{\circ}$ North, UVB radiation decreases markedly during the winter months of November through February. ${ }^{2}$ Thus, other sources of vitamin D, including dietary vitamin $\mathrm{D}_{2}$ (ergocalciferol), vitamin $\mathrm{D}_{3}$, and vitamin $\mathrm{D}$ supplements, are particularly important in Northern latitudes. ${ }^{2}$

Hypovitaminosis D is prevalent in both healthy and chronically ill Finnish children and adolescents. ${ }^{3}$ Vitamin D insufficiency (serum 25-hydroxyvitamin D [S-25-OHD] $<50 \mathrm{nmol} / \mathrm{L}$ ) is common in pediatric patients with malignancy due to poor diet, lack of sunlight exposure, and toxic effects of cancer therapy. ${ }^{4} \mathrm{~A}$ high body mass index (BMI) and older age may be additional risk factors. ${ }^{3,5}$

The aim of this single-center study was to evaluate the prevalence of vitamin D deficiency in children with hemato-oncological diseases, living in Northern Finland, for whom vitamin $D$ supplementation of $10 \mu \mathrm{g}$ /day was recommended.

\section{Methods}

This prospective cross-sectional study was conducted between November 2014 and February 2015 in a tertiary university hospital in Northern Finland. All the patients lived between northern latitudes $64^{\circ}$ and $70^{\circ}$. In total, 106 patients were eligible, and 101 (95\%) consented to participate. The patients were recruited from pediatric hematology and oncology outpatient and inpatient clinics, and all the patients were counseled to take vitamin D supplements of at least $10 \mu \mathrm{g}$ daily. Ethical approval was given by the Regional Ethics Committee of the Northern Ostrobothnia Hospital District (Ethical Approval Number 84/2014). Written informed consent was obtained from all the individual participants included in the study. Parental consent was obtained for participants under 16 years.

Clinical and demographic data were collected from the patients' files. A questionnaire was used to obtain information on the use of vitamin D supplements and other supplements, as well as dietary intakes. Vitamin D and calcium intakes were calculated from information on fish, egg, milk, cheese, and other dairy product consumption. ${ }^{6}$ Information on physical activity, bone fractures, the use of sunblock, and holidays in sunny regions was obtained via the questionnaire.

Blood samples were obtained from all the patients in the Nordlab laboratory of Oulu. ${ }^{7}$ S-25-OHD, parathyroid hormone, alkaline phosphatase, calcium, and phosphate were analyzed. Vitamin D deficiency was defined as $\mathrm{S}-25-\mathrm{OHD}<50 \mathrm{nmol} / \mathrm{L}$, and satisfactory, target, and excessive levels were defined as 50 to $75 \mathrm{nmol} / \mathrm{L}, 75$ to $200 \mathrm{nmol} / \mathrm{L}$, and $>200 \mathrm{nmol} / \mathrm{L}$, respectively, based on other studies $^{2-4,7}$ (Table 1).

\section{Statistical Analysis}

Differences in continuous variables between the 2 groups were tested by the Mann-Whitney $U$ test. An exact $\chi^{2}$ test was used to compare distributions between the 2 groups. A linear regression analysis was used to define independent variables associated with S-25-OHD levels. The statistical analyses were executed with IBM

\footnotetext{
'Oulu University Hospital, Oulu, Finland

${ }^{2}$ University of Oulu, Oulu, Finland

${ }^{3}$ University of Helsinki, Helsinki, Finland

${ }^{4}$ Helsinki University Hospital, Helsinki, Finland

${ }^{5}$ Karolinska Institute, Stockholm, Sweden

${ }^{6}$ Karolinska University Hospital, Stockholm, Sweden

${ }^{7}$ Uppsala University, Uppsala, Sweden

\section{Corresponding Author:}

Johanna Lumme, Department of Pediatrics and Adolescence, Oulu University Hospital, Box 23, 90029 OYS, Finland.

Email: johanna.lumme@student.oulu.fi
} 
Table I. Serum 25-OHD Levels and Definitions. Use of Vitamin D Supplementation With the Study Subjects.

\begin{tabular}{lcccc}
\hline & & \multicolumn{3}{c}{ Vitamin D Supplement } \\
\cline { 3 - 5 } Serum 25-OHD (nmol/L) & Definition & Yes, $\mathrm{n}=93, \mathrm{n}(\%)$ & No, $\mathrm{n}=8, \mathrm{n}(\%)$ & All, $\mathrm{n}=10 \mathrm{I}, \mathrm{n}(\%)$ \\
\hline$<50$ & Deficiency & $10(\mathrm{II})$ & $3(37)$ & $13(13)$ \\
$50-74.9$ & Satisfactory & $36(39)$ & $4(50)$ & $40(40)$ \\
$75-200$ & Target range & $47(50)$ & $\mathrm{I}(13)$ & $48(47)$ \\
\hline
\end{tabular}

Abbreviation: S-25-OHD, serum 25-hydroxyvitamin D.

SPSS Statistics for Windows, Version 22.0.0.2 (IBM Corp, Armonk, NY).

\section{Results}

\section{Characteristics of the Cohort}

There were 61 males and 40 females, and their mean age was 7.9 years (range $=0.5-18.6$, standard deviation $[\mathrm{SD}]=4.9)$. All but one patient of African origin were Caucasians. Sixty-two patients had malignant disease: acute leukemia $(n=37)$, lymphoma $(n=4)$, solid tumor $(\mathrm{n}=18)$, and central nervous system tumor $(\mathrm{n}=3)$; and 39 patients had benign disease. Sixty-four patients had received chemotherapy, and 28 patients had ongoing chemotherapy. Stem cell transplantation was performed for 11 patients.

The patients were classified into 4 categories based on weight (underweight, healthy weight, overweight, and obese) according to age- and sex-adjusted BMI (ISO-BMI: 2-18 year olds) and weight for height percent $(<2$ year olds $){ }^{8}$ Eight of the patients were underweight, 69 were of healthy weight, 19 were overweight, and 5 were obese.

\section{Vitamin D Status}

The median S-25-OHD level was $72.0 \mathrm{nmol} / \mathrm{L}$ (interquartile range $[\mathrm{IQR}]=58.0-84.5)$. Among the patients, S-25-OHD levels were inadequate in $13 \%$, satisfactory in $40 \%$, and at target levels in $47 \%$, and none had excessive levels (Table 1). The S-25-OHD levels of boys and girls were not significantly different (median $=74.0 \mathrm{vs}$ $70.5 \mathrm{nmol} / \mathrm{L}, P=.853$ ). The $\mathrm{S}-25-\mathrm{OHD}$ levels of those with malignant and benign diagnoses were also not significantly different $($ median $=71.5 \mathrm{vs} 75.0 \mathrm{nmol} / \mathrm{L}, P=$ .727). Furthermore, the S-25-OHD levels of patients with fractures were not significantly different from those without fractures $($ median $=71.0$ vs $72.5 \mathrm{nmol} / \mathrm{L}, P=$ .894). There was no association between S-25-OHD levels and weight $(P=.543)$, but there was a negative association between S-25-OHD levels and age $(P<.001)$. When age increased by 1 year, the S-25-OHD level decreased by $1.6 \mathrm{nmol} / \mathrm{L}(95 \%$ confidence interval =
$0.7-2.4)$. The mean serum parathyroid hormone level was $36.5 \mathrm{ng} / \mathrm{L}$, and it was not associated with S-25-OHD levels $(P=.187)$.

\section{Vitamin D Intake From Supplements and Food}

The median vitamin D supplement intake was $10.0 \mu \mathrm{g} /$ day $(\mathrm{IQR}=10.0-10.0)$. Among the patients, $92 \%$ used vitamin D supplements. Of those, $91 \%(85 / 93)$ used $\geqslant 10$ $\mu \mathrm{g}$ per day, and $16 \%(15 / 93)$ used $20 \mu \mathrm{g}$ or more. Nine of 10 patients with S-25-OHD levels below $50 \mathrm{nmol} / \mathrm{L}$ used $<10 \mu \mathrm{g} /$ day, and 3 of 8 patients who did not take vitamin D supplements had S-25-OHD levels below $50 \mathrm{nmol} / \mathrm{L}$. The S-25-OHD levels of the patients who took vitamin D supplements were higher (median $=75 \mathrm{nmol} / \mathrm{L}, \mathrm{IQR}=$ $61.5-86.0 \mathrm{nmol} / \mathrm{L}$ ) than those of the patients who did not take such supplements (median $=55.5 \mathrm{nmol} / \mathrm{L}, \mathrm{IQR}=$ 42.0-61.8, $P=.005)$. Most of the patients taking vitamin D supplements $(\mathrm{n}=93)$ had satisfactory S-25-OHD levels $(39 \%)$ or target levels $(50 \%)$. In contrast, most of the patients who did not take vitamin D supplements $(\mathrm{n}=8)$ were vitamin $\mathrm{D}$ deficient (37\%) or had only satisfactory S-25-OHD levels (50\%; $P=.028)$.

According to the dietary questionnaire, the median total vitamin D intake, including both supplements and food, was $18.8 \mu \mathrm{g} /$ day $(\mathrm{IQR}=16.1-24.9$; Table 2$)$. There was no association between vitamin $\mathrm{D}$ intake and age $(P$ $=.799)$. The S-25-OHD level increased by $0.6 \mathrm{nmol} / \mathrm{L}$ when overall vitamin $\mathrm{D}$ intake increased by $1 \mu \mathrm{g}(P=$ .022 ). Figure 1 shows the association between overall vitamin $\mathrm{D}$ intake and S-25-OHD levels in children with malignant $(\beta=0.4, P=.254)$ and benign $(\beta=1.0, P=$ $.009)$ diseases. The mean level of dietary vitamin $D$ resulting in the target level of S-25OHD $(>75 \mathrm{nmol} / \mathrm{L})$ was $22.5 \mu \mathrm{g}(\mathrm{SD}=7.6 \mu \mathrm{g})$. The lowest level resulting in vitamin D sufficiency was $11.4 \mu \mathrm{g}$. The median total calcium intake per day was $1.084 \mathrm{mg}(\mathrm{IQR}=825-1545)$.

\section{Discussion}

This cross-sectional study examined vitamin D intake and levels in a prospective cohort of children from Northern Finland who had hemato-oncological diseases 
Table 2. Calculations of Nutritional Vitamin D and Calcium Intake. Overall Nutritional Intake Is the Sum of Daily Doses.

\begin{tabular}{|c|c|c|c|}
\hline Nutrition and Portion Size & Vitamin D $(\mu \mathrm{g})$ & Calcium (mg) & \\
\hline Milk, I dL & I & 120 & \\
\hline Yogurt and other dairy products, I dL & I & 120 & \\
\hline Egg & 1.3 & - & \\
\hline Fish, portion $60 / 120 \mathrm{~g}^{\mathrm{a}}$ & 5 & - & \\
\hline Cheese slice $10 \mathrm{~g}$ & - & 91 & \\
\hline Overall Nutritional Intake & n (\%) & Mean & SD \\
\hline Fish (times/month) ${ }^{b}$ & $96(96)$ & 3.8 & 2.9 \\
\hline None & $4(4)$ & & \\
\hline Milk (dL/day) & & 5.7 & 3.3 \\
\hline Dairy products (dL/day) & & 2.2 & 2.4 \\
\hline Cheese slices (pieces/day) & & 2.6 & 3.1 \\
\hline Eggs (pieces/week) & & 1.3 & 1.6 \\
\hline
\end{tabular}

Abbreviation: SD, standard deviation.

${ }^{\mathrm{a}}$ For children $<12$ years old, fish portions are $60 \mathrm{~g}$; for children $\geqslant 12$ years old, fish portions are $120 \mathrm{~g}$.

${ }^{b}$ Oily fish + white fish + oily and white fish.

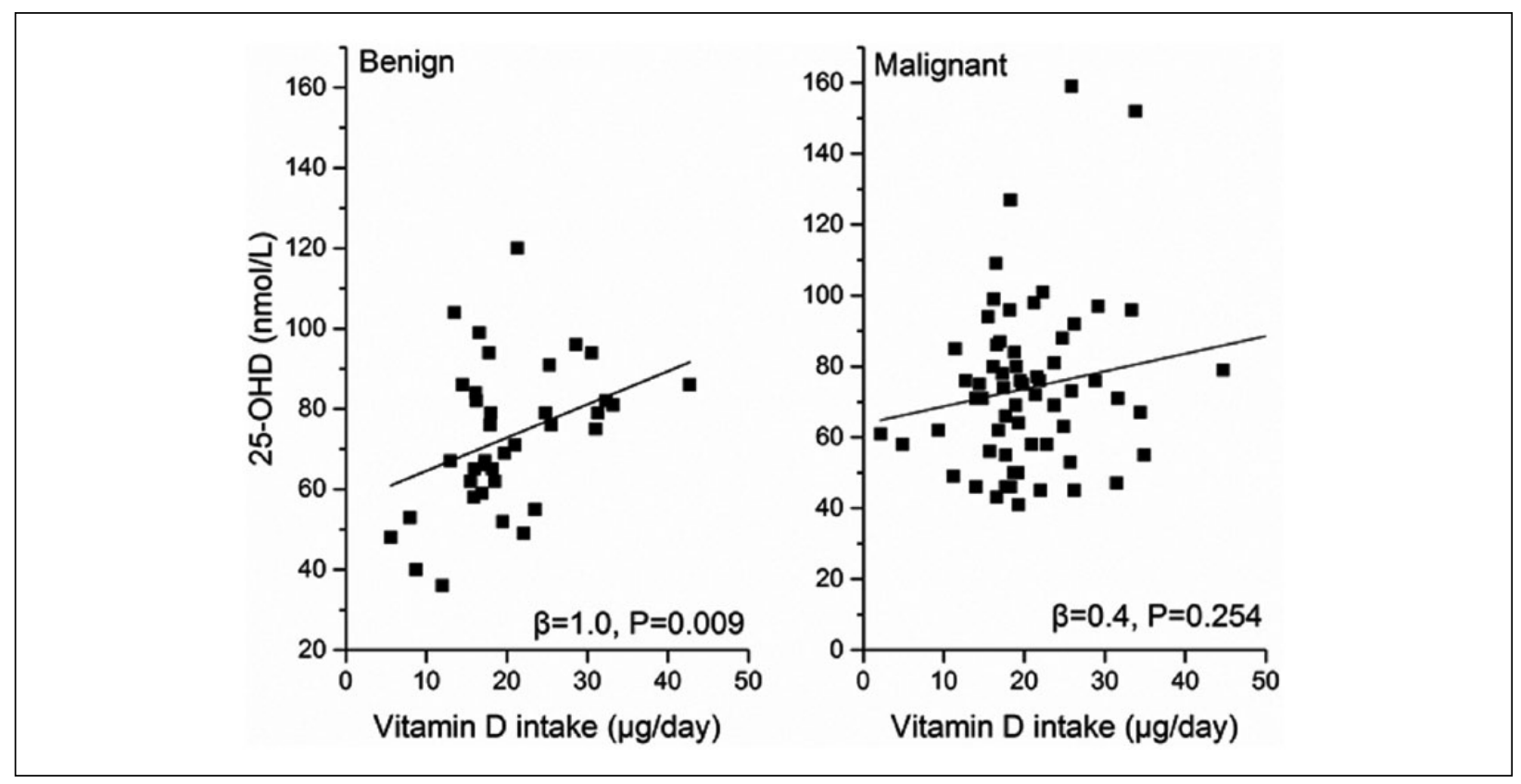

Figure I. Association between overall vitamin $D$ intake and S-25-OHD levels in children with malignant $(A ; \beta=0.4, P=$ $.254)$ and benign $(B ; \beta=1.0, P=.009)$ diseases. $S-25-O H D$ rose to $0.6 \mathrm{nmol} / \mathrm{L}$ when reported overall vitamin $D$ intake increased by I $\mu \mathrm{g}(P=.022)$.

Abbreviation: S-25-OHD, serum 25-hydroxyvitamin D.

and were instructed to take a vitamin D supplement (10 $\mu \mathrm{g} /$ day). Vitamin D levels were satisfactory in $87 \%$ of the patients, and almost half of the patients had S-25OHD within the target range. As expected, S-25-OHD levels were higher when vitamin D supplements were taken. Vitamin D deficiency was observed in only 13\% of the patients. Vitamin D supplementation has been recommended in Finland since the 1940s. ${ }^{9}$ The Current
Finnish Nutritional Council guidelines recommend vitamin D supplementation for all children and adolescents, with $10 \mu \mathrm{g} /$ day recommended for infants between 2 weeks and 2 years and $7.5 \mu \mathrm{g} /$ day for children between 2 and 18 years. ${ }^{10}$ Vitamin D supplementation of $10 \mu \mathrm{g} /$ day is recommended by our center for children receiving treatment for hemato-oncological diseases. This recommendation is based on earlier findings, which showed 
that such patients had a high risk of vitamin D insufficiency. ${ }^{4}$ Some of the patients received higher doses of vitamin $\mathrm{D}$ because the benefits of adequate vitamin D levels have received a great deal of public attention in Finland. Thus, the doses that some parents gave their children were higher than those officially recommended. In the present study, the median total vitamin D intake, including vitamin D from supplements and food, was surprisingly high $(18.8 \mu \mathrm{g} /$ day $)$. This can be explained by the high level of consumption of fish and the high concentration of vitamin $\mathrm{D}$ in dairy products $(1 \mu \mathrm{g} / \mathrm{dL})$. Among the vitamin-D-deficient patients, 90\% reported vitamin D supplementation of $\leqslant 10 \mu \mathrm{g} /$ day.

S-25-OHD levels decreased with increasing age, suggesting that older children have an increased risk of having inadequate vitamin D levels. Therefore, a higher dose of vitamin D supplementation, up to $20 \mu \mathrm{g} /$ day, should be considered for these children. Previous studies demonstrated that both healthy and chronically ill adolescents had a high risk of vitamin D deficiency. ${ }^{3,11}$ Vitamin D insufficiency has been reported to be common with high BMIs and among allogeneic stem cell transplantation patients. ${ }^{12}$ In the present study cohort, we did not observe similar findings.

\section{Conclusion}

Vitamin D supplementation of at least $10 \mu \mathrm{g} /$ day resulted in a satisfactory vitamin D status in most of the patients $(87 \%)$. None of the patients had excessive levels, even with supplemental doses that exceeded $10 \mu \mathrm{g} /$ day. Vitamin D supplementation can be recommended for chronically ill pediatric hemato-oncological patients, especially at latitudes where UVB exposure is insufficient. A higher dose than $10 \mu \mathrm{g} /$ day may be beneficial, especially in older children who have lower vitamin D levels than younger children.

\section{Author Contributions}

JL, MM, TP, OM, AHS and RN designed the study. JL, MM and $\mathrm{RN}$ were responsible for enrolling the patients in this study and collecting the data. JL and RN prepared the manuscript. TP was responsible for the data analysis. All authors edited and approved the final manuscript. All authors are accountable for the study.

\section{Declaration of Conflicting Interests}

The author(s) declared no potential conflicts of interest with respect to the research, authorship, and/or publication of this article.

\section{Funding}

The author(s) disclosed receipt of the following financial support for the research, authorship, and/or publication of this article: Johanna Lumme has received research funding from the Alma and K. A. Snellman Foundation, Oulu, Finland, and Outi Mäkitie has received research funding from the Swedish Childhood Cancer Foundation.

\section{ORCID iD}

Johanna Lumme (iD https://orcid.org/0000-0002-5774-1155

\section{References}

1. Holick MF. Vitamin D deficiency. $N$ Engl J Med. 2007;357:266-281.

2. Holick MF. Sunlight and vitamin D for bone health and prevention of autoimmune diseases, cancers, and cardiovascular disease. Am J Clin Nutr. 2004;80(6 suppl):1678S-1688S.

3. Holmlund-Suila E, Koskivirta P, Metso T, Andersson S, Mäkitie O, Viljakainen HT. Vitamin D deficiency in children with a chronic illness - seasonal and age-related variations in serum 25 -hydroxy vitamin $\mathrm{D}$ concentrations. PLoS One. 2013;8:e60856.

4. Modan-Moses D, Pinhas-Hamiel O, Munitz-Shenkar D, Temam V, Kanety H, Toren A. Vitamin D status in pediatric patients with a history of malignancy. Pediatr Res. 2012;72:620-624.

5. Shin YH, Shin HJ, Lee YJ. Vitamin D status and childhood health. Korean J Pediatr. 2013;56:417-423.

6. Fineli. Finnish food composition database. http://www .fineli.fi. Accessed November 25, 2015.

7. Misra M, Pacaud D, Petryk A, Collett-Solberg PF, Kappy M; Drug and Therapeutics Committee of the Lawson Wilkins Pediatric Endocrine Society. Vitamin D deficiency in children and its management: review of current knowledge and recommendations. Pediatrics. 2008;122:398-417.

8. Varimo T, Hero M, Laitinen EM, et al. Childhood growth in boys with congenital hypogonadotropic hypogonadism. Pediatr Res. 2016;79:705-709.

9. Hallman N, Hultin H, Visakorpi JK. Prophylactic use of vitamin D in Finland [in Swedish]. Duodecim. 1964;80:185-189.

10. Nordic Council of Ministers. Nordic nutrition recommendations 2012: integrating nutrition and physical activity. https://www.evira.fi/globalassets/vrn/pdf/nordic-nutritionrecommendations-2012.pdf. Accessed November 1, 2014.

11. Kumar J, Muntner P, Kaskel FJ, Hailpern SM, Melamed ML. Prevalence and associations of 25-hydroxyvitamin D deficiency in US children: NHANES 2001-2004. Pediatrics. 2009;124:e362-e370.

12. Esbenshade AJ, Sopfe J, Zhao Z, et al. Screening for vitamin D insufficiency in pediatric cancer survivors. Pediatr Blood Cancer. 2014;61:723-728. 